\title{
Parnasianismo y simbolismo en la encrucijada de la modernidad: hacia una revisión general de sus vínculos
}

\author{
Miguel Ángel FERIA VÁZQUEZ \\ Université Paris Diderot-Paris 7 \\ miguelangelferia@gmail.com
}

Recibido: 21/01/2015

Aceptado: 02/06/2015

\begin{abstract}
Resumen
Las poéticas del parnasianismo y el simbolismo configuraron la génesis de la propia poeticidad contemporánea. El objetivo de este artículo radica en revisar las interrelaciones entre ambas y su contribución a la superación del romanticismo y de la expresividad decimonónica a través de un análisis diacrónico de las mismas y a varios niveles, desde la epistemología a la retórica. Hacemos especial hincapié en la importancia del parnasianismo, la gran olvidada de todas las escuelas poéticas seculares, y en particular en su conexión con los autores que han sido considerados los padres del simbolismo. Centraremos finalmente nuestra atención en algunos condicionantes extraliterarios como las luchas de poder y el patriotismo y su contingencia en el devenir de las soluciones poéticas del Fin de Siglo.
\end{abstract}

Palabras clave: Poesía francesa, parnasianismo, simbolismo, Fin de Siglo.

\section{Le Parnasse et le symbolisme au carrefour de la modernité : vers une nouvelle approche de la relation entre ces deux mouvements}

\begin{abstract}
Résumé
Les poésies parnassiennes et symbolistes constituent la genèse de la poésie contemporaine. Le but de cet article est d'étudier les relations qui se tissent entre elles et leur contribution au dépassement du romantisme et à l'expression du XIX ${ }^{\mathrm{e}}$ siècle. Pour ce faire, on se propose d'analyser ces deux courants dans une perspective diachronique, épistémologique et rhétorique. Nous nous intéresserons tout particulièrement au Parnasse, grand oublié des écoles poétiques du siècle, et plus précisément à ce qui le lie aux auteurs considérés comme les pères du symbolisme. Dans une dernière partie, nous étudierons certains éléments extra-littéraires dont l'influence fut déterminante, tels que les luttes de pouvoir ou le patriotisme, dans l'évolution des solutions poétiques de la fin du siècle.
\end{abstract}

Mots clés : Poésie, Parnasse, Symbolisme, Fin de siècle. 


\title{
Parnassianism and Symbolism at the crossroads of Modernity. Towards a general review of their bonds
}

\begin{abstract}
Parnassianism and Symbolism constituted the origins of the contemporary poetry itself. The objective of this article is to study the interrelations between these poetic movements and their contribution to the overcoming of Romanticism and 19th century aesthetics. It will be done through a diachronic analysis of both poetic paradigms and at different levels, from epistemology to rhetoric. Special attention will be given to Parnassianism, the most forgotten secular poetic school, and particularly to its connections to the authors that have been considered the fathers of Symbolism. Finally, the focus will be centered in some extra-literary determining factors like power struggles and patriotism and their role in configuring the poetic solutions at the turn of the century.
\end{abstract}

Key words: Poetry, Parnassianism, Symbolism, Fin de siècle.

Sumario: Parnasianismo, simbolismo, epistemología y expresión. Baudelaire y la alegoría parnasiana: el eslabón encontrado. Tránsfugas del Parnaso, maestros del simbolismo. De la batalla por la trascendencia a la guerra contra el invasor.

\section{Referencia normalizada}

Feria Vázquez, M. Á. (2015). "Parnasianismo y simbolismo en la encrucijada de la modernidad: hacia una revisión general de sus vínculos”. Thélème. Revista Complutense de Estudios Franceses, Vol. 30, Núm. 2 : 203-221. http://dx.doi.org/10.5209/rev_THEL.2015.v30.n2.47774

\section{Parnasianismo, simbolismo, epistemología y expresión}

Cualquier intento de clarificar las correlaciones y disyunciones entre el parnasianismo y el simbolismo ha de responder a una voluntad de esclarecer la propia génesis de la poesía moderna. Surgidas en una época de intenso conflicto entre las acepciones artísticas de lo viejo y lo nuevo, ambas poéticas, sucesivas cronológicamente, acabaron conviviendo en una tensa impermutabilidad de sus soluciones expresivas que no impidió, sin embargo, algún que otro conato de asimilación mutua.

En primer lugar, debe entenderse el simbolismo como una recuperación del propósito poético del romanticismo original, es decir, el de sustrato germánico. Para A. Balakian (1969: 29), “desde el comienzo del movimiento romántico, la poesía se ha apropiado del terreno de lo místico como una especie de sucedáneo de la religión: los románticos buscaban analogías o imitaciones del infinito, y lo mismo hicieron los simbolistas”. Por su parte el parnasianismo, literatura de severos, empíricos, positivos contornos formales, estilísticos y conceptuales, vendría a suponer un luminoso paréntesis clasicista, de impronta grecolatina, entre dos noches septentrionales, la romántica y la simbolista. Al rechazar el componente positivista tan arraigado en parnasianos y naturalistas, el simbolismo se desinteresó de la aplicación literaria de la historia y de las ciencias para orientarse por una suerte de 
realización religiosa, mística, del arte, respondiendo así a una epistemología esencialmente distinta a la de aquéllos.

Sin duda, la praxis literaria del simbolismo venía a conformar artísticamente la crisis espiritual del Fin de Siglo en su máxima expresión. Si el poeta parnasiano se había retraído de su sociedad, renegando de las utópicas pretensiones humanitarias del bardo romántico, el simbolista no haría más que agudizar ciertas posturas heterodoxas encarnando un complejo renacer místico y espiritual absolutamente opuesto a la Weltanschauung positivista. El vacío de creencias posterior a la muerte de Dios pregonada por Nietzsche devino en una suerte de florecimiento de doctrinas -teosofismo, ocultismo, espiritismo...- que pretendían llenar ese mismo vacío con posturas cada vez más alejadas de la oficialidad. Y la poesía no haría más que proseguir esa búsqueda en el seno de lo que Manuel Serrat Crespo (2001: 30) denominara "una batalla por la trascendencia".

El símbolo como sistema epistemológico y como figura retórica aparece desde el alba de los propios textos literarios: al servicio de toda cosmovisión trascendente, un símil, una metáfora, una alegoría, una imagen son recursos retóricos que hilvanan la historia de la literatura universal. La originalidad de los simbolistas reposaba en la configuración radicalmente inédita que hacían del símbolo. El simbolismo trataba de prescindir del primer objeto de una correspondencia para evocar directamente el segundo, tal como argumentaba Jules Lemaître ( $C f$. Raymond, 1960: 43): "Una comparación prolongada de la que únicamente se nos da el segundo término, un sistema de metáforas seguidas”. En la polémica encuesta realizada por Jules Huret en 1891, Mallarmé confrontaba en estos términos su flamante poética con la de sus viejos amigos los parnasianos: "les Parnassiens, eux, prennent la chose entièrement et la montrent: par là ils manquent de mystère; ils retirent aux esprits cette joie délicieuse de croire qu'ils créent. Nommer un objet, c'est supprimer les trois quarts de la jouissance du poème” (Cf. Delvaille, 2003: 16). Para Mallarmé, el pecado mayor del parnasianismo radicaba en su énfasis referencial, en que representaba directa, explícitamente las cosas de la naturaleza. Desde el posicionamiento teórico del autor de Hérodiade, el verdadero arte literario no obedecía a la representación de los objetos, sino a su alusión al sesgo. Comenzando por la propia subjetividad, entendida como una misteriosa sugestión del alma del poeta, de un état d'âme complejo, híbrido, aleado de impresiones sin discriminación radical ni definición absoluta, y nunca como dictado de la emoción en sus categorías simples -tristeza, miedo, amor, etc.

La lírica simbolista procuraba impregnar con el matiz de un estado interior toda realidad objetiva; un estado que sólo el lector iniciado en los misterios de este arte moderno estaría en disposición de descifrar. A este respecto, G. Pellissier señalaba que "Delante de un paisaje el parnasiano dará en los términos más justos y netos que le sea posible lo percibido por su ojo; el simbolista [...] traducirá la correspondencia de este paisaje con su alma” (Cf. Casado, 1991: 51). Desde la óptica del simbolista, se trataba de sugerir una íntima correspondencia subjetiva entre lo exterior y lo interior mediante una expresión poética absolutamente novedosa, para lo cual se sirvió de mecanismos retóricos -o más bien cabría decir 
antirretóricos- de distinta naturaleza. En el transcurso del Parnaso al simbolismo se hallan, a propósito de la escritura descriptiva, los factores que reconducen la relación unívoca entre objeto y sujeto hacia la fusión polívoca de uno y otro, hacia una sola atmósfera sensible y sensibilizada.

Durante el apogeo del simbolismo, la poesía no se quiso más un arte de mera representación, sino de creación y experimentación. Para Mallarmé la poesía debía abandonar los procedimientos descriptivos tradicionales, ya obsoletos, para guiarse no por los descarados estados de ánimo románticos ni por los espectáculos parnasianos del mundo exterior, sino por el propio lenguaje puramente autorreferencial. En la acepción romántica, el símbolo afirmaba la profundidad del mundo y del yo: así Le Lac de Lamartine no significaba sólo un marco para la ensoñación romántica, sino una equivalencia anímica expresada con franqueza demasiada franqueza. El simbolismo finisecular llevó más allá dichos presupuestos basándose en el arte de la sugerencia, de la evocación de una idea abstracta desde una realidad concreta afinando así el trascendentalismo y extremando el subjetivismo -que no el sentimentalismo- románticos.

También supera en este sentido, a despecho de su fidelidad a una métrica estricta, el poema mallarmeano al poema pretendidamente objetivo del parnasiano. Si los poemas parnasianos, artefactos perfectamente bellos, representaban una imagen fragmentada del mundo incontaminada por la sentimentalidad del yo, a medio camino entre una subjetividad explícita y otra implícita, la poesía de S. Mallarmé aspira a un ideal absoluto en que se funden lo uno y lo otro: frente a la expresión del sujeto en mí del romanticismo o del objeto en sí del parnasianismo, la impresión del objeto en mí. El poema concentra todo un universo, cada palabra contiene todas las significaciones, inmanentes y trascendentes, y los símbolos coexisten en sus múltiples formas conjugando entre ellos infinitas correspondencias de sentido. Ya no se trata de la palabra-signo del romanticismo y del Parnaso, de esa palabra utilitaria que denota a lo interno o a lo externo, sino de la palabra-símbolo, de la palabra mágica que se referencia a sí misma en una red de infinitas connotaciones atributivas, en un caleidoscopio de metáforas prolongadas con el que habría de ensimismarse a partir de entonces el poeta moderno.

\section{Baudelaire y la alegoría parnasiana: el eslabón encontrado}

En la rehabilitación de algunas formas y procedimientos retóricos clasicistas tal el poema alegórico ha de situarse una de las claves del nacimiento de la nueva poética. Entre ellos, y como destaca J. A. Millán Alba (2000: 78), la "concisión del poema, perfecto equilibrio de sus partes, progresión metafórica que desemboca o puede desembocar en alegoría, recuperación de la mitología clásica y abandono de la bíblica, [...] preciosismo de las imágenes, [...] ida hacia el hermetismo del poema”. Aunque el Romanticismo, en general, había desestimado la alegoría como forma poética por ser "demasiado mecanicista como artefacto de producción de sentido, demasiado racional y demasiado didáctica: demasiado ligada a un medievalismo didáctico" (Ídem: 89), no dudaron en recurrir a ella Alfred de Vigny en varios de 
sus Poèmes Antiques et modernes, Víctor Hugo en piezas de Les Voix intérieures como "La Vache" o Alfred de Musset en la célebre imagen del pelícano de "La Nuit de mai”. Pero una recuperación sistemática de la alegoría no se encuentra más que en algunos maestros del Parnaso como Leconte de Lisle - "Le Parfum impérissable"- y sobre todo Théophile Gautier -"Les Colombes”, "Niobé”, "Le Pot de fleurs", "Le Pin des Landes", etc.

Partiendo de Gautier, Baudelaire presentaba en Les Fleurs du mal composiciones como "L’albatros", "Le masque”, “À une Madone (Ex-voto dans le gôut espagnol)", "Duellum” o el rotulado precisamente "Allégorie”, cuyo empleo del símbolo a la manera clásica, basado en una imagen asociada a una idea que se descifra siempre al final del poema, presenta lo que Jerónimo Martínez Cuadrado (2000: 205-206) reconoce como "aprosdóqueton, por el que el segundo término de la comparación no se hacía esperar mediante una ponderación en el primer término". En la alegoría, a diferencia de los procedimientos propiamente simbolistas tal cual los concebían Mallarmé y Jules Lemaître, comparecen siempre los dos términos de la analogía: al albatros, no duda en explicitarlo el propio Baudelaire, "Le Poète est semblable", como anteriormente, para Gautier, "le poète est ainsi” como aquel pino de las Landas.

Menos didáctico pero no más moderno resultaba igualmente el hábito baudelairiano de presentar en mayúsculas algunos sustantivos-clave esparcidos a lo largo de su obra: "Mort”, "Ennui”, "Esprit”, "Beauté”, testimonio cabal de un razonamiento todavía alegórico y apenas distanciado de los maestros románticos. A este procedimiento versal no fueron ajenos tampoco los poetas parnasianos: JoséMaria de Heredia, en algunos de sus Trophées como "L’Oubli”, agrupó múltiples sustantivos mayúsculos como "Mort", "Terre" o "Mer", en tanto que en piezas primerizas como "La Conque” (1866) o "La Mort de l’Aigle” (1864) se sirvió del soneto propiamente alegórico a la manera de Gautier y Baudelaire. También Catulle Mendès hizo lo propio en "Septembre", o Sully-Prudhomme en "Le vase brisé", "Les Danaïdes" o "La Jacinthe".

Como puede observarse, el Parnaso sí tuvo, aunque fundamentalmente a través de la alegoría, sensibilidad para percibir la posibilidad sígnica de las cosas. Pero en cualquier caso se trataba de un simbolismo discursivo, convencional, de carácter unívoco, centrado en una personificación de los abstractos a través de la cual aparece siempre "una idea previa que se debe exponer versificándola, y la imagen es el artificio adecuado para ilustrarla, como quien colorea el dibujo de otro. (...) La imagen carece de otro valor que el auxiliar y esa perspectiva degrada sus componentes" (Casado, 1991: 61). La alegoría, al cabo, tiende a clarificar los conceptos, y el simbolismo a oscurecerlos. En este primer estadio de su retórica simbólica, Baudelaire no dejaba de ser un poeta parnasiano. Desde las huestes del propio simbolismo, la diferencia entre alegoría y símbolo se presentaba con total claridad. Maurice Maeterlinck se percató de que era necesario "designar como alegoría la obra del espíritu humano en donde la analogía es artificial y extrínseca; llamaré símbolo a aquella en la que la analogía aparece natural e intrínseca”. Para Maeterlinck existían dos clases diferentes de símbolo, el símbolo a priori, 
concepción intelectual de intención deliberada, propiamente alegórica, y el símbolo a posteriori, inconsciente, interiorizado, el cual sucede sin que intervenga el poeta, como a pesar suyo: "el símbolo más puro es aquel que acontece sin que se dé cuenta e incluso en contra de sus intenciones" (Cf. González, 2000: 29-38) ${ }^{1}$.

Por más que prefigure el paso del romanticismo y el Parnaso hacia el decadentismo, el simbolismo y el porvenir, y pese a la silueta de genio aislado que privilegian muchas páginas exegéticas y hagiográficas, Baudelaire no vivió de espaldas a su contexto literario, y en su obra, es menester recalcarlo, existen amplios segmentos escritos a la maniera parnasiana. Hay quien sólo ve en la célebre dedicatoria a Gautier de Les Fleurs du mal la mera adulación de quien aspiraba a codearse con los autores prestigiosos. Pero lo cierto es que Baudelaire siempre consideró a Gautier uno de sus grandes maestros: como a tal le consagró varios estudios críticos, como a tal le dedicó íntegro su poemario con aquellas elogiosas y sinceras palabras: "Au poète impeccable / Au parfait magicien dès lettres françaises / A mon très-cher et très-vénéré / Maître et ami / Théophile Gautier...”.

Gautier, fundamentalmente, se había encargado de transmitir a Baudelaire las fórmulas del Arte por el arte, que junto a la Filosofía de la composición del americano Edgar A. Poe dotaron a su concepción literaria de herramientas primarias. Del Gautier “impeccable” asimiló Baudelaire, más allá de su pasión por la forma perfecta, su predilección por ciertos procedimientos retóricos como la propia alegoría y por algunos temas y motivos provenientes del romanticismo pintoresco. De ahí que no fueran los célebres Émaux et camées la obra de Gautier que tuvo en más alta estima el discípulo, sino sus libros anteriores, de mayor resabio romántico y carga alegórica ${ }^{2}$. Aunque en Les Fleurs du mal puedan rastrearse las huellas de Émaux et camées en piezas como "Les Sept viellards", la cual retoma motivos -y versos enteros, como el segundo- de "Vieux de la vielle", el Gautier que prevalece en el poemario de Baudelaire sigue siendo el de España, cuyo poema "L’Horloge”, por ejemplo, inspiró el homónimo "L’Horloge” de la sección "Spleen et idéal”, y

\footnotetext{
${ }^{1}$ En el ámbito hispanoamericano, el modernista nicaragüense Santiago Argüello trazaba una distinción entre ambos conceptos heredera de Maeterlinck: "Hay algo parecido al símbolo con el que a veces se confunde: la alegoría. Pero ésta es apenas un concepto, una abstracción mental expresada por un signo sin vida; mientras el símbolo es la Vida infinita expresada por un ser que vive. La alegoría es una significación intelectual. El símbolo una adivinación intuicional. La alegoría significa. El símbolo es” (1935: 98).

${ }^{2}$ En una primera redacción de la dedicatoria de Les fleurs du mal, luego desechada, Baudelaire había afirmado que "he querido rendir un profundo homenaje al autor de Albertus, de La comedia de la muerte y de España”, obliterando así la existencia de Émaux et camées (Cf. Verjat; Martínez Merlo, 2000: 73). Por otra parte, en el ensayo que dedicase a Gautier en L'Artiste (13 de marzo de 1859) Baudelaire se quejaba de la escasa fama del poeta de Tarbes reprochando al público que "todavía no ha tenido nadie ni tiempo ni dinero, según parece, para leer Albertus, La Comedia de la muerte y España” (Cf. Vázquez, 1999: 193).
} 
cuyas descripciones del Sacromonte acumuladas en el Voyage en Espagne resuenan en "Bohémiens en Voyage". De Émaux et camées Baudelaire se limitó a aplaudir, según él mismo declaró en un célebre artículo, el oficio del versificador, su aptitud para aquilatar "de manera sistemática y continua la majestuosidad del alejandrino en el octosílabo", así como su talento para la transposición artística, "la fusión del doble elemento, pintura y música, por la cuadratura de la melodía y por la púrpura regular y simétrica de una rima rigurosamente exacta” (Baudelaire, 1999: 220-221) ${ }^{3}$.

En lo que respecta exclusivamente a la métrica, la poesía de Baudelaire ha de ser considerada bajo una absoluta fidelidad a los patrones parnasianos, a su severa conciencia compositiva, opuesta al desaliño romántico. La férrea organización de sus secciones, cuyo celoso orden estructural y disposición arquitectónica reivindicó en todo momento, y en un orden interno, el mecanismo de relojería que regía cada composición, dotaron a Les Fleurs du mal de ese sello de época que garantizaba su procedencia del taller parnasiano. Ya en su Salón de 1846 había afirmado que "no hay azar en el arte, como tampoco lo hay en la mecánica” (Baudelaire, 2000: 1120), aforismo digno de Gautier o Leconte de Lisle. La rigurosa técnica, la riqueza de la rima, el conservadurismo acentual de su alejandrino clásico, la búsqueda del efecto sonoro, su sumisión a las exigencias del soneto y de otras formas fijas de estructura más compleja aprendidas de su amigo Banville -por ejemplo el pantoum oriental de "Le Balcon"- hacen de Baudelaire, en este sentido, uno de los grandes estilistas del Parnaso.

Valiéndose de una versificación tan parnasiana, Baudelaire canalizó sin embargo una cosmovisión personalísima, inédita entre los miembros de su generación. Su revolucionaria concepción de la belleza y del arte traspasaba con creces los limitados planteamientos del Parnaso, a cuya belleza clásica, históricamente prefijada, cristalizada en el canon grecolatino, opuso una suerte de demonización plagada de imprecaciones y disonancias, viva expresión de los abismos interiores y de la contradictoria existencia íntima y social del hombre moderno. Si la poesía de Théodore de Banville procuraba fundamentalmente agradar a los sentidos, y la de Leconte de Lisle satisfacer a la vez un anhelo de belleza plástica y pensamiento filosófico, Baudelaire invitaba a contemplar al ser humano en su pleno significado de carnalidad moral, de una sensualidad transida de complejos, pasiones, deseos, sombras. Su visualización de lo femenino exaltaba una belleza bifronte cuya expresión más común se sustentaba en un amplio desarrollo del oxímoron: "Le Masque (statue allégorique dans le gôut de la Renaissance)", "Hymne à la Beauté", "XXV (Tu mettrais l'univers dans ta ruelle)" o "Le Possédé" así lo ilustran. Frente a la pretendida imparcialidad parnasiana en la exposición de los temas, la poesía de Baudelaire expresa rectamente las realidades exterior e íntima. Su sensibilidad

\footnotetext{
3 “Théophile Gautier” se publicó por vez primera en L’Artiste, el 13 de marzo de 1859. Citamos la traducción que Lydia Vázquez incluye en su edición de Baudelaire (1999), Crítica literaria. Madrid, Visor.
} 
estremecida y estremecedora rompe con la voluntad altiva y solemne del Parnaso para exponerse a sí misma, al homo duplex teñido de claroscuros, euforias y traumas; eso sí, sin rebajarse en ningún momento a las sensiblerías elegíacas del romanticismo tardío, las cuales despreciaba profundamente. El rebelde ego baudelairiano, omnipresente en su obra, venía a tender un puente entre el yo romántico y el yoísmo decadente por encima de uno de los grandes dogmas de la Escuela parnasiana, la objetividad.

Atento a su circunstancia, Baudelaire no volvió los ojos a Grecia ni a las civilizaciones antiguas, y a la vieja Atenas prefirió París, quintaesencia de la metrópolis moderna. Por más que retomen algunos aspectos de la poesía urbana de Gautier -ya se han citado las concordancias entre "Les Sept viellards" y "Vieux de la vielle"-, sus "Tableaux parisiens" sentaban las bases del mito literario del París contemporáneo como no se había hecho hasta entonces. La diferencia entre ambos radica en el sujeto poético, no en el objeto. Aunque Gautier recorriera las mismas calles y salones que su coetáneo pupilo -al que sobrevivió en un lustro-, fue Baudelaire quien supo aclimatar su yo lírico a los aspectos más actuales de la ciudad moderna, entre ellos el anonimato (Cf. Azúa, 1999: 155-164). A diferencia de los parnasianos, Baudelaire no dedicó un solo poema a celebrar la belleza clásica, y el mismo año cuando aparecieron los Poèmes antiques de Leconte de Lisle (1852) no dudó en ridiculizar a esa escuela pagana a la cual pertenecían, en el fondo, sus mejores amigos (Vid. Baudelaire, 1999: 113-120).

Baudelaire, a diferencia de Gautier y de los parnasianos, logró hallar la manera de sobrepasar los estrechos márgenes de aquella retórica convencional en la cual un albatros acababa irremediablemente transfigurado en poeta. La mayor valentía de Baudelaire no radicó en provocación moral o religiosa alguna, sino precisamente en esta intrepidez para soltarse de la mano del didactismo y del puro silogismo leído en Swedenborg, en Poe, en Hugo o en Gautier; en su falta de prejuicios para trastornar el razonamiento lógico del poema y la estructura argumentativa tradicional -léase en este sentido "De profundis clamavi"-. En palabras de Anna Balakian (1969: 2728), "cuando Swedenborg dice que jardín significa sabiduría, que los árboles son el conocimiento del bien y el pan el amor, todo esto es anticuada alegoría y no símbolo". Mucho se ha hablado del valor fundacional del soneto "Correspondances". Ello no ha de ponerse en duda en lo que atañe a teorización simbólica, pero en la práctica simbolista aquellos versos permanecen aún religados a la interpretación alegórica: "La Nature est un temple où de vivants piliers..." (Baudelaire, 2000: 94): he aquí el didactismo, los dos términos de la analogía, el sustantivo-clave en mayúsculas. No se debe, por lo tanto, a poemas como "Correspondances" que Baudelaire haya de ser considerado el padre del simbolismo. $\mathrm{Su}$ valor real radica, por el contrario, en haber sabido ejecutar una verdadera traslación de las correspondencias entre lo abstracto y lo concreto al terreno de lo objetivo y lo subjetivo. Ya no se trataba de una dualidad entre lo terrenal y lo celeste que el poeta tenía que descifrar, sino de una interacción entre todas las experiencias sensoriales, no espirituales, que se establecen en el interior de un sujeto, y cuya última interpretación corre a cargo del propio yo que percibe el 
fenómeno. De la verticalidad a la horizontalidad, del intelectualismo al sensualismo: he ahí la esencia del impresionismo sinestésico y de la sugerencia baudelairiana, las auténticas enseñanzas que legaría al simbolismo. No está de más traer a colación piezas como "Harmonie du soir", en la cual se sugiere una proyección silenciosa del yo lírico en las imágenes del atardecer: aquello ya no era romántico ni parnasiano.

La superación de las poéticas subjetiva del romanticismo y objetiva del Parnaso se concretiza en la obra de Baudelaire mediante una fusión de ambas, no explícitamente, sino por la pura sugerencia. Sin embargo, Baudelaire, en su obra lírica, aún no arriba plenamente a lo que pueda juzgarse una retórica ni una poeticidad pura a la moderna, es decir, exenta de desarrollo lógico, argumentativo, anecdótico, narrativo o descriptivo, más propia del simbolismo inaugurado por Mallarmé. Recordemos, por otra parte, que Baudelaire, como bien indica Pedro Provencio (2002: 29), “abominó de los poemas en que Mallarmé comenzaba a emplear una distorsión lingüística opuesta a la fluidez que siempre acompañó al verso baudeleriano".

¿Y la prosa baudelairiana? Aquí radica, en última instancia, el auténtico rompimiento de los rigurosos límites de la métrica y la expresividad parnasianas. Aquí confluye la búsqueda de una música interior que se acomodase con naturalidad a las ideas y a los temas del poema y a las sensaciones y ensoñaciones del yo lírico. Sin duda, los poemas en prosa de Baudelaire significaron, más que sus versos, el verdadero nacimiento de la expresión lírica simbolista y moderna. Contra la narratividad y el hilo discursivo lógico, aquel fragmentarismo milagroso de una "prosa poética y musical, aunque sin ritmo ni rima" que tradujese "los movimientos líricos del alma" abría definitivamente las puertas de la poesía a las posibilidades de la sugerencia y del verso libre, según dejó escrito el poeta en la dedicatoria a A. Houssaye que abre El Spleen de Paris. La musicalidad semántica y no fonológica ni morfosintáctica, la armonía más abstracta que física de aquellos textos venían a dejar definitivamente atrás cuanto Banville fijara, dignificara y defendiera a muerte en el más parnasiano de todos los tratados, el Petit traité de poésie française, en cuyas páginas se negaba con rotundidad la mera posibilidad de una lírica en prosa. Frente al vacuo discurso de la norma, el estilo, la tendencia y el arabesco líricos, Baudelaire proponía definitivamente una liberación, sin vuelta atrás, de los componentes semiológicos y retóricos de la lengua poética heredada.

\section{Tránsfugas del Parnaso, maestros del simbolismo}

La vía libre hacia el simbolismo inaugurada por Baudelaire hubo de ser recorrida, partiendo de su ejemplo, por varios autores que en un principio participaron de los dogmas parnasianos y se rebelaron contra la Escuela desde su propio seno; aquellos que, como declara Javier del Prado refiriéndose a Rimbaud, "lucharon parnasianamente contra el Parnaso" (2001: 60).

Para Verlaine, Rimbaud o un Mallarmé recién expulsado del tercer y último Parnasse contemporain (1876) la poética parnasiana había quedado obsoleta justo 
cuando los parnasianos comenzaban a gozar de la consagración oficial de crítica y público, a revisar sus obras completas, a pasarse en masa de la vanguardia a la retaguardia literaria. Ya hacia 1867, los más jóvenes miembros decidieron desertar del Salón de Leconte de Lisle para refugiarse en los cafés y cabarets de ambiente libertino -tanto en lo moral como en lo literario-. En 1871, el grupo "Le Cercle des Vilains Bonhommes", compuesto por Verlaine, Rimbaud y otros escindidos del Parnaso como Léon Valade tenía por principal ocupación parodiar agriamente, en su colectivo Album Zutique, a los románticos y a los parnasianos. Este Album Zutique exhibía una larga serie de poemas rotulados "Vieux Coppées" en los cuales se hacía burla del célebre autor de Le Passant y Les Humbles imitando su estilo realista, melodramático y cursi, aunque no sería François Coppée el único asiduo a los salones de la Escuela en sufrir las mofas de los "Vilains Bonhommes"4.

Si Baudelaire había encarnado al más auténtico prototipo, con los "Vilains Bonhommes" nacía oficialmente para la literatura finisecular la figura del poeta maldito, héroe marginal que poco guarda ya en común con los viejos maestros parnasianos, pulcros eruditos, estetas, bibliófilos, cada vez más alejados de la bohemia, la mayoría llamando a las puertas de la Academia Francesa. El parnasianismo tenía en la sacralización de la tradición artística y literaria uno de sus fundamentos insoslayables, mientras que esta joven vanguardia se habría de caracterizar justo por lo contrario: iconoclastas, herederos de Villon, de Rabelais, de Béranger, no dudaron en arrastrar a la poesía a los dominios de lo lúdico y lo satírico, desfrunciéndole el ceño adusto a las helénicas estatuas del Parnaso. En 1884 ve la luz Les poètes maudits de Paul Verlaine, obra que presenta al público un nuevo canon de escritores cuya poética antiparnasiana plasma la sensibilidad del decadentismo y del simbolismo nacientes. Allí, en cada comentario, lo que para Verlaine constituían las virtudes de un autor eran precisamente aquellos elementos que más lo alejaban del parnasianismo: léase, en este sentido, la introducción a Tristan Corbière...

Quien fuera en sus inicios acérrimo integrante del Parnaso pronto abanderó la más cruda reacción, y como señaló Mallarmé, fue Verlaine "le premier qui a réagi

\footnotetext{
${ }^{4}$ Verlaine no abandonaría esta lúdica costumbre a lo largo de toda su vida. Así, pueden leerse otros "Vieux Coppées" compuestos en la época de Sagesse entre los que se hallan sátiras de una dureza brutal contra todo el Parnaso, desde el propio Coppée -"Pour charmer tes ennuis, ô temps qui nous dévastes / Je veux, durant cent vers ocupes en dizains chastes / Comme les ronds égaux d'un même saucisson, / (...) À l'instar de Monseur Coppée et des cigales” (Verlaine, 1977: 396) - hasta José-Maria de Heredia -vid. "Retour de Naples”. Aparte de los “Vieux Coppées”, Verlaine escribió, con motivo del ingreso en la Academia de Leconte de Lisle, una durísima invectiva en la que tachaba al maestro, entre otras cosas, de pedante, de servil y de "perro zalamero" (Cf. Pujol, 1992: 133-134). Por su parte, los pastiches del Parnaso con los que Rimbaud contribuyó al Album Zutique dirigían sus flechas contra Armand Silvestre -"Lys"-, Léon Dierx -"Les lèvres closes”-, Gautier -"Vieux de la vieille”-, Louis-Xavier de Ricard -"L'Humanité”-, Coppée -a lo largo de siete "Vieux Coppées”-, Catulle Mendès -“Conneries”- y... Paul Verlaine -"Féte Galante”.
} 
contre l'impeccabilité et l'impassibilité parnassiens” (Cf. Campa, 1998: 54). Su primer libro, Poèmes saturniens (1866) se mantenía aún apegado a las doctrinas de la Escuela, según arrojan sus diferentes dedicatorias -Coppée, Mendès, etc.- como las numerosas piezas que denotan su clara filiación a la poética de Leconte de Lisle: "Prologue”, "Épilogue”, "Un Dahlia”, "Marco”, “César Borgia”, "La Mort de Philippe II”, "Çavitrî”... Pero incluso aquí éstas alternan con otras varias, pergeñadas con la sensación intimista y la dicción rayana en la oralidad, en las que se presiente ya a un Verlaine impresionista en su huida de la robusta elocuencia parnasiana.

Fêtes galantes (1869) venía a proponer un paso más hacia el consciente alejamiento del parnasianismo de su autor. La atmósfera de ensoñación vaga y melancólica, el deseo de no comunicar el estado subjetivo directamente, sino de cubrir lo biográfico con una pátina de imágenes y metáforas sensoriales, en fin, el arte de la sugerencia a través del cual un paisaje exterior suministra el motivo para un sentimiento interior, todo ello sumado a los desfallecimientos sintácticos conforman una red de elementos que anticipan los rasgos fundamentales del simbolismo. La mitología, por ejemplo, ya no aparecía bajo la luz grandilocuente del historicismo de Leconte de Lisle, sino a través de un velo de trivialidad e incluso humorismo que en parte remitía al ejemplo de las Odes funambulesques de Théodore de Banville. Fêtes galantes será, en cualquier caso, la última obra de Verlaine con manifiestos anclajes parnasianos. Con una técnica descriptiva impresionista que privilegiaba, en su búsqueda del matiz sugerente, el uso de adjetivos poco específicos -incierto, gris, huidizo... Verlaine descubría para la poesía de su tiempo que las palabras que connotan emoción tienen más poder comunicativo que las que denotan a la emoción misma. Resulta importante, a este respecto, el concepto de elipsis: suprimir al máximo lo anecdótico para valorar lo fragmentario conlleva, como contrapartida, una potenciación de la comunicación efectiva del sentimiento al suprimir precisamente la comunicación plena y recta del mismo, en una suerte de estilización de la insinuación afectiva más propia del erotismo moderno que del desnudo artístico clásico. Ello tiene sus implicaciones retóricas, y frente al "esculpe, lima, cincela" del arte poética de Gautier, el poema verlainiano se interpreta musical, no escultóricamente. El mármol se vuelve humo, y la perspectiva, música. La sólida escultura parnasiana no servía ya para traducir los matices del alma, lo impreciso, la sugestión, los sueños, los malestares e inquietudes del espíritu moderno. ¿YY de qué recursos se valió Verlaine para expresar dicho espíritu? Una de sus principales aportaciones resultaba sin duda del cambio tonal que imprimió a sus poemas, con sus ritmos quebrados, coloquialismos, ironías e indolencias expresivas, trivialidad, humor, pleonasmos... La oralidad y el impresionismo musical del poema verlainiano rompían así con el retoricismo parnasiano de manera unilateral, como el propio autor expuso en su célebre "De la musique avant toute chose...”

Si Verlaine lo hizo a través de una concepción fundamentalmente antirretórica de la renovación lírica, la ruptura con la expresión parnasiana que Mallarmé encarnaba se fraguó en mayor medida en el ámbito de la abstracción conceptual y la 
densidad metafórica. Desde sus primeras composiciones, incluso entre las incluidas en las primeras entregas de Le Parnasse contemporain se advierte una preocupación por renovar los componentes simbólicos del poema ajena a la ortodoxia de la Escuela parnasiana. En uno de sus primeros comentarios a "Herodiade", cuya versión más temprana data de 1864 y la definitiva de 1867, Mallarmé se mostraba ya plenamente consciente de la nueva poeticidad que inauguraba. La brecha entre la vieja y la nueva poética se irá agrandando hasta situar a Mallarmé en el trono mayor de la poesía simbolista, honor por el cual ha pasado a la historia de la literatura. Sus nociones de epistemología aplicados a la poética rebasaban ya todos y cada uno de los preceptos del parnasianismo. La expresión indirecta de Mallarmé se fue transformando en algo tan privado y tan hermético que escasos lectores y apenas los propios poetas simbolistas estuvieron realmente preparados para proseguir aquellas coordenadas, y la inmensa mayoría de sus jóvenes alumnos optó, sobre todo en el mundo hispánico, por los modos verlainianos, cuyo universo íntimo, aunque velado y elíptico, no oscurecía hasta tal punto la comunicación poemática.

Por su parte, la poesía de Arthur Rimbaud, por inaudita en su contexto y por no hallar efectiva continuidad hasta pasadas varias décadas después de su escritura, resultó más radical aún que la de los precitados. Sin ninguna filiación personal con el grupo de poetas parnasianos, a los que aborrecía -con la excepción de Banville-, el genio adolescente se presentó como un fulgor en los círculos más vanguardistas del París literario de su tiempo, y con la misma premura desapareció de los mismos. Si sus primerísimos versos son los propios de un colegial aplicado, cuya asimilación de la manera de los maestros resultaba sorprendente, el gran Rimbaud nada debería luego al Parnaso. Cierto es que en 1870 intentó darse a conocer enviando varios poemas a Théodore de Banville para Le Parnasse contemporain, los mismos que nunca serían publicados ${ }^{5}$. De entre todos ellos conviene destacar el titulado "Soleil et chair", ejercicio de estilo parnasiano que bien podría haber figurado en cualquiera de las recopilaciones organizadas en torno al editor Alphonse Lemerre. Se trata de la composición del Rimbaud aspirante a parnasiano de mayor filiación con los dogmas de la Escuela: filosofía materialista y panteísta, mitología literaria y plástica, sonoridad exótica del culturalismo, perfección formal. Otras composiciones como “Ophélie" o "Tête de Faune” también exhibían rasgos análogos, aprendidos de Banville, su primer maestro y precisamente por eso, el primero del que tuvo que renegar el joven iconoclasta. Pero la influencia del Parnaso en Rimbaud no se aleja en lo esencial de la que recibieron todos los jóvenes de su generación que estudiaban y escribían a la sombra de la tendencia dominante.

\footnotetext{
${ }^{5}$ En concreto, los llamados Manuscritos de Théodore de Banville están formados por cinco poemas, remitidos en dos cartas de mayo de 1870 y de agosto de 1871, cuando ya Rimbaud había comenzado su particular temporada en los infiernos. Apenas cinco piezas en las que, como señala Javier del Prado (2001: 40), el poeta "marca su admiración y su distanciamiento (ironía, sinceridad) respecto del gran poeta y respecto del Parnaso".
} 
Fueron sus últimos versos, sus prosas, en fin, sus obras maestras las que patentizaban cómo el simbolismo, siguiendo el ejemplo de los Verlaine y Mallarmé, probó a descoyuntar la concepción poética, rígida en lo formal y en lo conceptual, del Parnaso. La exposición sugerente para Rimbaud reposaba en la desconexión y en la yuxtaposición de los elementos lingüísticos más que en la incertidumbre del matiz anímico o nominativo, aunque no por ello dejara de servirse de los hallazgos verlainianos y mallarmeanos. Dueño de su propia "videncia poética”, su concepción literaria, mientras la tuvo, no fue otra cosa que un intento, en palabras de Javier del Prado (2001: 59), de "recuperar la dimensión trascendente de la poesía que sus abuelos depositaron en la Divinidad o en la Humanidad y que sus padres sólo habían sido capaces de buscar en la Belleza”. Contra sus abuelos románticos y sus padres parnasianos, la batalla por la trascendencia de Rimbaud se libró en un campo al que sólo él había llegado por entonces. ¿Pues qué opinión tuvieron los parnasianos de su obra? Una ceguera que ilustran bien las palabras de Catulle Mendès, cuya barbarie crítica puede extrapolarse a otros miembros de la Escuela:

[Rimbaud est] un exaspéré Romantique attardé [...]. [Il est un] réactionnaire frénétique et non pas un novateur, [...] de sorte que, malgré un très réel talent estimé de tous les lettrés, Arthur Rimbaud, qui dut une gloire peu répandue à un généreux complot d'amicales louanges et quelque renommée moins restreinte à l'aventure mystérieuse de sa vie, ne semblera guère dans l'avenir, je pense, qu'un Petrus Borel naturaliste (1903: 117).

\section{De la batalla por la trascendencia a la guerra contra el invasor}

Toda vez que la juventud literaria de los Ochenta asimiló plenamente y supo conjugar las innovaciones de Baudelaire y de los tránsfugas del Parnaso aconteció entonces un fecundo desenvolvimiento del decadentismo-simbolismo que amenazaba con borrar del mapa literario a todo aquello que no se regía por su mismo espíritu, por su absoluta renovación de los cánones. En este sentido un joven seguidor de Zola, Joris-Karl Huysmans, devino en auténtico patriarca de la Decadencia promoviendo una nueva sensibilidad estética con su novela À Rebours (1884). Su protagonista, Jean Floressas des Esseintes, alter ego del autor, prestaba su voz a una reacción que, llevando a sus extremos el esteticismo y el culto de la artificialidad parnasianos, pregonaba un nuevo orden de belleza y de expresión literaria, próximo a veces a lo anormal y lo antinatural. El parnasianismo le era ya insuficiente, y así en el capítulo XIV, dedicado a la poesía, des Esseintes dejaba claro que la juventud había ido sustituyendo los modelos de la Escuela por una nueva forma de hacer y entender la lírica, encarnada por Baudelaire y por prosélitos como Verlaine, Mallarmé, Corbière, Jean Richepin o Charles Cros.

Los centros neurálgicos de la poesía decadente-simbolista se trasladaron del viejo barrio parnasiano de Montparnasse al de Montmartre, cuyo famoso cabaret, Le Chat noir, reunía a toda la juventud bohemia junto con autores de relativa fama. Allí leyó por vez primera Verlaine su célebre soneto "Langueur”, cuyo primer verso -“Je suis l’Empire à la fin de la décadence”- habría de adoptarse como una suerte de manifiesto del decadentismo anterior a la aparición de la revista Le Décadent 
(1886). Las lecturas poéticas que en el cabaret tenían lugar reflejaban el sincretismo de toda una marabunta de acentos líricos, poses extravagantes y versos funambulescos - de todos los parnasianos, tan sólo Banville participó en aquellas veladas- que pregonaban una poesía de aires nuevos, ajena a la preceptiva de la Escuela. Las inevitables burlas contra Coppée, "poète mort Jeune”, o las sinfonías cromáticas llevadas al extremo del desorden sensorial ilustraban, en pleno corazón del París literario, la gestación del movimiento simbolista (Cf. Velter, 1996: 17 y Ss.).

En aquel contexto no se haría esperar el Manifiesto Simbolista de Jean Moréas, publicado en Le Figaro el 18 de septiembre de 1886. Partiendo de las enseñanzas de Mallarmé, Moréas repudiaba allí varios de los rasgos primordiales del parnasianismo: “enemiga de la enseñanza, de la declamación, de la falsa sensibilidad, de la descripción objetiva, la poesía simbolista busca vestir la idea de una forma sensible, que (...) no sería su propio objeto, sino que, al servir para expresar la idea, permanecería sujeta...” (Cf. Martino, 1948: 179). En 1886, las expresiones símbolo y arte sugestivo se multiplicaban por doquier en reseñas y ensayos de crítica literaria, y ese mismo año se publicó el Traité du Verbe de René Ghil, donde tales cuestiones eran profusamente auspiciadas. Con un prefacio de Mallarmé, el libro exponía lo que Ghil denominaba "instrumentación verbal", flamante teoría sobre los constituyentes del verso opuesta radicalmente al Petit traité de poésie francaise de Banville, manual vigente aún en los salones de la Escuela.

En este punto, cabría preguntarse cómo se vivió en general la revolución simbolista desde las filas del Parnaso, aspecto éste que hasta ahora no ha suscitado toda la atención que merece. La orgullosa reivindicación del símbolo poético provocó una manifiesta indignación entre los sectores no simbolistas, entre los no iniciados, en tanto que, como queda dicho ya, se trata de un recurso tan viejo como la propia literatura. Procedimientos simbólicos de diferente índole habían sido comunes a los románticos y a los parnasianos, de ahí las objeciones de los mismos a un acaparamiento que consideraban a todas luces, aunque sin razón suficiente, pura provocación generacional antes que auténtica y original propuesta lírica. Así se preguntaba Catulle Mendès (1903: 96):

Le Symbole, qu'est-ce? Après les significations purement historiques, les dictionnaires disent: Figure ou image employée comme signe d'une chose. Les dictionnaires ne disent pas tout: le Symbole nous apparaît, au point de vue poétique, à la fois plus vaste et en même temps plus spécialisé. [...] Les poètes appelés symbolistes n’auraient rien inventé du tout.

José-Maria de Heredia expresaba un sentimiento análogo al de su compañero de armas: "Mais pourquoi diable s'appellent-ils symbolistes? [...] Tous les poètes sont symbolistes! [...] Seulement, il y en a d'obscurs et de clairs” (Cf. Mortelette, 2005: 
395). El extenso Testamento poético de Sully-Prudhomme, por su parte, arroja importantes conclusiones sobre la postura del Parnaso frente al inminente triunfo simbolista $^{6}$. Allí el primer Premio Nobel de Literatura de 1901 comenzaba por mostrarse intransigente con las innovaciones que en materia de sintaxis pretendían introducir en la poesía francesa los jóvenes simbolistas: "la sintaxis [...] es esencialmente impersonal [...] pero el hecho de no someterse a sus leyes denota ignorancia de la gramática, decisión de ser inteligible o alguna pretensión literaria subversiva” (Sully-Prudhomme, 1965: 650). Para ilustrar sus teorías, SullyPrudhomme confesaba haber recuperado todos los ejemplos de los que se sirvió Banville en su Petit traité de poésie française, declarándose incluso más ortodoxo que el maestro en lo que respecta a ciertas cuestiones como los versos impares. La división radical entre verso y prosa, y por lo tanto, la imposibilidad del poema en prosa y de la mezcla de géneros, quedaría expuesta con la misma rotundidad que en el tratado de Banville: "La armonía del verso es superior a la de la prosa, merced a unos recursos musicales completamente peculiares. Nada más opuesto, tanto al genio francés como a la esencia misma de la versificación, como consagrar ésta exclusivamente al servicio de las emociones poéticas” (Ídem: 653).

El segundo capítulo de este Testamento poético, "Sobre la diferencia entre la prosa y el verso", resulta capital para comprender el enfrentamiento entre Parnaso y simbolismo en los aspectos que atañen a la pura expresión poética, pues se basa en la correspondencia cruzada en 1887 entre un parnasiano como el propio SullyPrudhomme y un joven de aspiraciones simbolistas, Adolphe Boschot, autor de La crisis poética. Boschot, a quien "aterran los parnasianos", recoge el guante lanzado por Sully-Prudhomme para que explicase la versificación, la prosodia, la sintaxis y aquel híbrido del poema en prosa, a lo que el joven respondería de esta guisa:

Me pregunta usted reiteradamente "qué es lo que a mis ojos distingue la prosa del verso". Confieso que no lo sé con exactitud. [...] Pero, ¿qué objeto tienen [...] todos esos esfuerzos por dar rigidez geométrica a lo que es movible y matizado? ¿por qué no atenerse a la impresión subjetiva que produce la obra de arte? [...] Y, lo más funesto, ¿por qué insistir sin discreción sobre un concepto abstracto, sobre el verso, sobre "el verso en sí”, instrumento y medio de expresión, considerado aparte de toda melodía y de toda expresión anímica, tal como pudiéramos considerar un cornetín o un clarinete separadamente de la música? [...] Quiere usted utilizar la razón y legislar, olvidando que en arte no existe más regla que el instinto y el gusto. [...] Mallarmé expresa esto muy bien. [...] Una forma de verso no dura mucho más que una generación de poetas. Y entonces, ¿por qué pretende usted someter la generación que empieza a la métrica parnasiana? ¿Cree haber usted encontrado una métrica eterna? (Ibídem: 685).

Las réplicas y contrarréplicas entre parnasianos y simbolistas se sucederían sin que se llegara a acuerdo alguno, como es lógico. En 1893 el editor y principal benefactor de la Escuela parnasiana, Alphonse Lemerre, proyectaba un cuarto

\footnotetext{
${ }^{6}$ Publicado en distintos opúsculos desde 1892, cito el texto integrado en Obras escogidas. Poesía (edición bilingüe) y prosa. Traducción y prólogo de J. A. Fontanilla. Aguilar, Madrid, 1965.
} 
Parnasse contemporain que nunca hubo de ver la luz. Se han conservado sin embargo los prospectos y anuncios del editor, los cuales marcaban la orientación radicalmente parnasiana de la antología, encumbrando la poética de la Escuela y atacando de paso a Mallarmé y al simbolismo en general. Dichos textos esgrimen auténticas declaraciones de guerra, e ilustran la visión reaccionaria que una parte del Parnaso -el propio Lemerre, François Coppée, Catulle Mendès, SullyPrudhomme...- tenía de las nuevas propuestas literarias. Uno de los dardos más afilados de Lemerre iba dirigido contra los nuevos procedimientos expresivos, oscuros demonios que el simbolismo acababa de desatar, entre ellos las "lignes de longueur variable, tantôt rimées, tantôt assonancées, tantôt ni rimées ni assonancées, des vocables employés sans tenir compte de leur sens traditionnel mais seulement de leur couleur ou de leur pouvoir suggestif...” (Cf. Mortelette, 2005: 375).

El tradicionalismo de Lemerre y del conjunto de los parnasianos frente a la poesía joven atañe no sólo a conceptos formales y más o menos ornamentales tal la ortografía, sino a las propias raíces de la poética simbolista, a la sugerencia, a la sinestesia, a la autonomía de los significados con respecto a toda la tradición semántica anterior. Para Lemerre, "La poésie n'est pas un art de pure suggestion; à la différence de la musique, elle doit exprimer -exprimer d'abord- et suggérer tout ensemble" (Cf. Mortelette, 2005: 377). En su opinión, los últimos que estuvieron en el secreto de la autentica lírica francesa fueron los parnasianos, quienes aún "savent trop que les mots n'ont pas seulement un son, mais une figure et comme une physionomie; et que le plaisir esthétique que donnent les vers n'est pas seulement auditif mais, dans une certaine mesure, visuel” (Cf. Mortelette, 2005: 377).

El auge del versolibrismo y del hermetismo conceptual del simbolismo juntó filas en el Parnaso, reactivando así su pretérita voluntad común de luchar contra la decadencia de la forma poética y la excesiva inclinación a la abstracción del romanticismo. Para el parnasiano, el poeta no sólo tenía que someterse a unos medios de expresión bien definidos, sino también a un discurso lógico y racional. En este sentido, muchos fueron los hombres de la Escuela que reconocieron no comprender los poemas simbolistas. Así lo declaraba abiertamente, por ejemplo, el maestro Leconte de Lisle: "Mon opinion, elle est simple: comme je ne comprends absolument pas ce qu'ils disent, ni ce qu'ils veulent dire... je n'en pense absolument rien!” (Cf. Mortelette, 2005: 395). Al analizar las relaciones entre el parnasianismo y el simbolismo hay que tener siempre presente un conflicto generacional, amén de poético, con el telón de fondo de la lucha por conquistar un status literario-social. El Fin de Siglo francés asistió así a una guerra abierta entre unos jóvenes poetas que trataban de arrebatar fama y posición a ciertos antecesores ya consagrados: por entonces, y por dar algunos ejemplos relevantes, ocupaban un sillón académico Sully-Prudhomme, François Coppée y Leconte de Lisle, todos condecorados además con la Cruz de la Legión de Honor. Hablar, por tanto, de los parnasianos es hablar, por esas fechas, de los poetas oficiales de la III República y de los blancos predilectos para las jóvenes revistas que sucedieron al manifiesto de Moréas. Del lado de los parnasianos, tanto los aludidos como Catulle Mendès devolvían golpe por golpe desde sus poderosas tribunas de la prensa, poniendo en 
duda el valor literario del simbolismo y tachando a sus obras de "mélopées imprécises” (Mendès, 1903: 150).

Fueron momentos propicios para el florecimiento de las encuestas literarias, en las cuales se enfrentaban abiertamente ambas tendencias, tratando de atraer hacia sí a los poetas de un bando u otro. Así, Henri de Régnier era pretendido por los parnasianos al tiempo que Léon Dierx lo fue por los simbolistas. Las dos falanges procuraban también hallar aliados para su causa entre los grandes poetas del presente y del pasado, los parnasianos celebrando a Hugo y los simbolistas a Baudelaire, Mallarmé y Verlaine. A veces se llegó a tal extremo que la crítica contra el simbolismo se transformó en ardiente defensa del patriotismo literario, dada la evidente aportación extranjera a la configuración de la nueva poética, desde la literatura anglófona -Poe, Carlyle, Swinburne, los prerrafaelitas...- pasando por la rusa, la escandinava o por la figura capital de Richard Wagner. Un simple vistazo a las declaraciones de los parnasianos arroja a la luz cierto número de palabras clave -“race", "traditionnel”, "français”, etc.- cuya recurrencia mucho dice al respecto.

Así, una de las mayores acusaciones que el Parnaso dirigiera contra el simbolismo radicaba en su ruptura con la tradición secular francesa. Para Mendès (1903: 151), los simbolistas "saccagèrent la technique qu'ils jugeaient vieillie, que je crois éternelle”. Los parnasianos no dudaron en apoyarse en la noción de raza con el fin de justificar el respeto a la tradición, afirmando que el versolibrismo era antifrancés en base a que la versificación francesa se fundaba sobre la duración del verso y no sobre la prosodia. En cuestiones de métrica, Mendès oponía el romanticismo, revolución desde el interior del verso francés, al versolibrismo preconizado por los simbolistas, moda impuesta por corrientes extranjeras. En su respuesta al discurso de ingreso en la Academia de José-Maria de Heredia, François Coppée no dudaría en deplorar del simbolismo "on ne sait quel vent d'est, chargé de brume germanique" (Cf. Mortelette, 2005: 397), términos que sin duda recuerdan a los españolísimos y célebres "suspirillos germánicos” con que Núñez de Arce había ridiculizado la poesía de hálito becqueriano. El propio Heredia, a su regreso de un viaje a Cuba, y sorprendido por la cantidad de poetas extranjeros que se agrupaban en los cenáculos simbolistas, llegaría a decir que "me sorprende ver que sean los belgas, suizos, griegos, ingleses y americanos quienes pretendan renovar la poesía francesa" ${ }^{7}$. En fin, la mayoría de los parnasianos atribuyeron a un supuesto desconocimiento del genio de la lengua francesa el cosmopolitismo del movimiento simbolista, abanderado por autores de origen griego como Moréas o americano como Stuart Merrill.

\footnotetext{
${ }^{7}$ Incluso el propio Paul Verlaine se lamentaba del creciente extranjerismo que parecía hacerse con las riendas del simbolismo francés: "Ya no es verso, es prosa, y muchas veces tontería. Y sobre todo, no es francés. ¡Somos franceses, gracias a Dios!” (Cf. Balakian, 1969: 117-120).
} 
Pese a todo lo apuntado hasta ahora, las rivalidades entre el parnasianismo y el simbolismo no deben hacer obviar sus coincidencias, mayores en el espíritu que en la letra cuando se tienen en cuenta, fundamentalmente, las corrientes líricas amparadas por la burguesía dominante, que al fin y al cabo eran las que acaparaban el mayor número de lectoras y lectores en la época. Ambas poéticas surgieron a contrapelo de su tiempo, buscando el refinamiento artístico y rechazando el realismo en favor del idealismo. La fantasía funambulesca de Banville, su experimentación métrica, junto a la simbología mitológica de Leconte de Lisle insuflaron muchos de sus elementos a la nueva generación poética. Buena parte de los temas y motivos convencionales del Parnaso -cisnes, piedras preciosas, figuraciones históricas, representaciones ecfrásticas...- serían luego reinterpretados por el simbolismo, aunque desde el nuevo código expresivo que venía inaugurando. No debe olvidarse, por otro lado, que a veces también los simbolistas escribieron valiéndose de un estilo directo de significado unilateral, ora subjetivo, ora objetivo, cuando no alegórico a la vieja manera de Gautier o Baudelaire, un hecho que desembocaría en una suerte de neoparnasianismo finisecular sustentado, a ráfagas, por autores como Henri de Régnier -Les Médailles d'argile- o Albert Samain -Aux Flancs $d u$ vase. Sin la depuración parnasiana de la lengua poética, el simbolismo no habría alcanzado su propia depuración conceptual ni los medios técnicos para sugerirla. La teoría de la sensación prolongada, de la facultad que posee un verso para inducir al lector a un estado de ensoñación fue materia ya discutida en el Salón de Leconte de Lisle, por más que no se lograran allí las materializaciones posteriores. Los parnasianos decidieron abstraerse de la realidad refugiándose en la contemplación estética: la poesía del Arte por el arte supuso a este respecto el primer paso hacia la utopía lingüística tal y como luego la desarrollaría Mallarmé en su obra. Los discípulos de Mallarmé buscaron desarrollar las implicaciones filosóficas de la creación de un mundo a través del lenguaje, pero fueron los parnasianos los primeros en establecer el carácter inmanente de ese mundo, los primeros en vislumbrar dicho creacionismo lingüístico mediante la noción de poema-artefacto artístico.

Todos estos aspectos resultan esenciales a la hora de considerar el nacimiento de la poesía contemporánea. Entre el subjetivismo racionalista del romanticismo y el subjetivismo irracionalista del simbolismo, fueron capitales los esfuerzos de una poesía objetiva, de una despersonalización crucial para el paso de lo uno a lo otro. La sustitución de lo explícito por lo implícito en el transcurso del retoricismo y la elocuencia al impresionismo, a la economía expresiva, a la sugerencia conllevó definitivamente la superación del romanticismo, del Parnaso y por ende de todo el siglo XIX. El arte simbolista patentó, frente a una expresividad agotada, el recurso de la sugerencia, umbral de todo el irracionalismo moderno, piedra filosofal de la lírica contemporánea tallada en primera instancia por un artífice de la Escuela parnasiana para su inminente transmutación en panacea lírica. 


\section{REFERENCIAS BIBLIOGRÁFICAS}

Argüello, S., (1935) Modernismo y modernistas. Guatemala, Tipografía Nacional.

Asselineau, Ch., (2004) Charles Baudelaire. Su vida y su obra. Edición y traducción de P. Rovira. Valencia, PreTextos.

Azúa, F. de, (1999) Baudelaire y el artista de la vida moderna. Barcelona, Anagrama. Balakian, A., (1969) El movimiento simbolista. Madrid, Guadarrama.

Baudelaire, Ch., (1997) Pequeños poemas en prosa (El Spleen de París). Traducción de E. López. Castellón. Madrid, M. E. Editores.

Baudelaire, Ch., (1999) Crítica literaria. Edición de L. Vázquez. Madrid, Visor.

Baudelaire, Ch., (2000) Las flores del mal. Edición bilingüe de A. Verjat y L. Martínez de Merlo. Madrid, Cátedra.

Campa, L., (1998) Parnasse, Symbolisme, Esprit nouveau. París, Ellipses.

Casado, M., (1991) "Introducción” a Verlaine, P., La buena canción. Romanzas sin palabras. Sensatez. Madrid, Cátedra.

Del Prado, J., (2001) “Introducción” a Rimbaud, A., Poesías completas. Madrid, Cátedra.

Delvaille, P. (ed.), (2003) Poètes Symbolistes. París, La Table Ronde.

Gautier, Th., (2004) Oeuvres poétiques complètes. Edición establecida por M. Brix. París, Bartillat.

González, A., (2000) "Introducción” a Maeterlinck, M., La intrusa. Los ciegos. Pelléas y Mélisande. El pájaro azul. Madrid, Cátedra.

Mallarmé, S., (2001) Poesía completa. Edición bilingüe de P. Mañé. Barcelona, Libros Río Nuevo.

Martínez Cuadrado, J., (2000) "La función del poeta francés del siglo XIX según sus creadores" in Anales de Filología Francesa. N ${ }^{\circ} 9$ (Homenaje al profesor D. Francisco Martín Más), pp. 205-226.

Martino, P., (1948) Parnaso y Simbolismo. Traducción de E. Ramos. Buenos Aires, El Ateneo.

Mendès, C., (1903) Rapport sur le mouvement poétique française de 1867 à 1900. París. Ed. facsímil editada por Slatkine Reprints, Ginebra-París, 1993.

Millán Alba, J. A., (2000) "Introducción” a Baudelaire, Ch., Poesía completa. Escritos autobiográficos. Los paraísos artificiales. Crítica artística, literaria y musical. Madrid, Espasa.

Mortelette, Y., (2005) Histoire du Parnasse. París, Fayard.

Provencio, P. (de), (2002) Poemas esenciales del Simbolismo. Barcelona, Octaedro.

Prudhomme, S., (1965) Obras escogidas. Poesía (edición bilingüe) y prosa. Traducción y prólogo de J. A. Fontanilla. Aguilar, Madrid.

Raymond, M., (1960) De Baudelaire al surrealismo. Traducción de J. J. Domenchina. México, Fondo de Cultura Económica.

Serrat Crespo, M., (2001) "Introducción” a Lautréamont: Los Cantos de Maldoror. Madrid, Cátedra.

Velter, André (ed.), (1996) Les Poètes du Chat Noir. París, Gallimard.

Verlaine, P., (2000) Los poetas malditos. Introducción y edición de R. Pérez. Traducción de M. Bacarisse. Bilbao, Muelle de Uribitarte. 